\title{
Information and communications technology adoption amongst township micro and small business: The case of Soweto
}

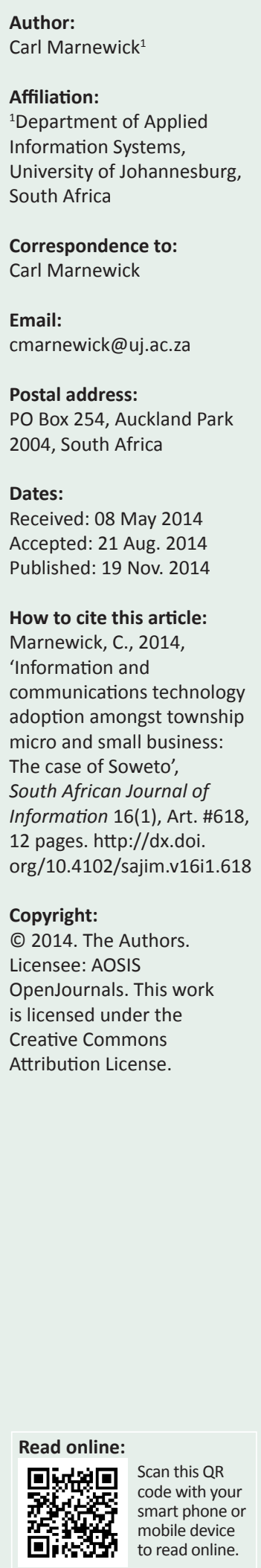

Background: No empirical evidence is available on whether or not information and communications technology (ICT) is adopted by South African township micro and small businesses (MSBs) in order to grow the business. ICT, as an enabler, can grow the business. It is evident from literature that ICT enables MSBs to be more productive and efficient.

Objectives: This research determines to what extent ICT is adopted by MSBs in Soweto, and whether or not a positive correlation exists between the adoption rate of ICT and the financial and growth performance of the MSB itself.

Method: A structured questionnaire was completed by 978 respondents to determine the extent of ICT adoption and for what ICT is used. This exploratory research provides new knowledge about the acceptance of ICT within township MSBs.

Results: The results indicate that ICT is not used to the fullest by MSBs. Rather, it is used as a basic tool for doing business but it does not form an integral part of the business. This research provides insight into the usage and adoption of ICT and it opens the door for further crossanalysis research.

Conclusion: Education and training are needed to ensure that MSBs use ICT to the fullest. MSBs embracing ICT can evolve from a survivalist SME to a more sustainable micro and small MSB.

\section{Introduction}

Small and medium enterprises (SMEs) are the heartbeat of any country's economy. This is even more so in developing countries where SMEs are responsible for employment and the growth of the economy (Beck, Demirguc-Kunt \& Levine 2005; Cravo, Gourlay \& Becker 2012). One aspect that can assist SMEs in growing the business is information and communication technology (ICT). Management literature highlights the value of ICT and information in the organisational context (Hu \& Plant 2001). ICT can enable SMEs to achieve these goals, of employment and growth, if it is adopted and incorporated into the day-to-day management of the SME.

There is currently no empirical evidence of whether or not micro and small businesses (MSBs), as a special type of SME, in townships adopt any type of ICT to grow the business. The term township originated in the apartheid era and began when non-white people (black people, people of mixed-race and Indians) were limited to living near or working in white-only communities. Township MSBs play a major role in the creation of wealth and employment within the realm of townships, as there are no other forms of employment in those areas (Mbonyane 2006). According to SBP (2013):

The contribution that small business makes in generating employment is near universally recognised. So is the corollary acknowledgement, that a healthy and much expanded small business community could be a keystone of a new economic deal for South Africa. (n.p.)

The argument is that ICT, as a business enabler, should be capable of assisting MSBs if it is adopted by the MSBs. ICT provides an opportunity for MSBs to improve their efficiency and effectiveness, and even to gain competitive advantage (Arendt 2008; Thong \& Yap 1995). Research carried out, on rural SMEs in the United States of America (USA) in the late 1990s, concluded that SMEs will only adopt ICT if there is a perception that ICT will assist in overcoming a business problem or opportunity (Premkumar \& Roberts 1999:470). Some of the benefits mentioned by the SMEs that had adopted ICT were reduced turnaround time, increased transaction speed, access to current information and reduction in data entry errors (Premkumar \& Roberts 1999:482). There are, however, SMEs that deliberately did not adopt any ICT. One of the reasons was that the SMEs did not find any need for these technologies in their businesses. 
This research is innovative as it highlights that township MSBs do not adopt ICT and that interventions are needed to cross the digital divide in townships. The results provide statistical information on the 'raw' rates of ICT adoption for a sample of MSBs in the township of Soweto. This research also provides a baseline for future research. Future research can include comparative analysis of various MSBs as well as SMEs in various townships, and analysis of developed and developing countries.

Studies within the discipline of ICT adoption have not focused on SMEs or, for that matter, MSBs within townships. Instead, research has been focused on traditional companies and SMEs and how ICT enabled those organisations to perform financially (Lucchetti \& Sterlacchini 2004; Premkumar \& Roberts 1999; Thong \& Yap 1995).

This research addresses the lack of empirical knowledge with regard to ICT adoption and usage within township MSBs. An understanding of the problem provides various possibilities for South Africa. Firstly, the adoption of ICT will increase the revenue of the individual MSBs and ultimately the growth of the economy at large. Secondly, it also provides focus areas where ICT and the type of ICT can and should be deployed to assist MSBs.

A structured questionnaire was circulated amongst MSB owners within Soweto. This was circulated through a survey consultancy company that interviewed the population. This company deployed resources, the personnel of which interviewed the various SMB owners. The interviewers were briefed on the purpose of the research, and additionally about how each question related to the overall research hypotheses. The data were then captured and analysed using SPSS.

The article is divided into four sections. The first section focuses on the literature of MSBs, as well as the technology adoption model (TAM), and how it can and should assist MSBs in the growth of the economy. The second section focuses on the research methodology and how the results were collected from the various respondents. The third section is an analysis of the results of the 978 respondents, and focuses on the type of ICT that the MSBs used as well as the business reasons that the ICT was used. The fourth and last section specifies the impact of ICT adoption and the consequences of adopting or not adopting ICT within the realm of township MSBs.

\section{Literature review}

The value of the small business sector is recognised in economies worldwide which is irrespective of whether it is a developed or a developing economy (Thurik \& Wennekers 2004; Hotho \& Champion 2011). According to Mahembe (2011:13): 'the contribution towards growth, job creation and social progress is valued highly and small businesses are regarded as an essential element in a successful formula for achieving economic growth'. The contribution of SMEs in
South Africa to the economy is summarised as per Table 1. The World Bank (2006), however, estimated that SMEs would contribute $39 \%$ to the generation of employment whereas China's SME sector contributed 78\% to its total employment. This is an area of concern given the high unemployment rate in South Africa. SMEs can bridge this gap.

According to Mandisa Mpahlwa, the former South African Minister of Trade and Industry, the small business sector in 2006 comprised 2 million small businesses which present almost $98 \%$ of the total number of South African companies (Njiro, Mazwai \& Urban 2010). Collectively SMEs employed $55 \%$ of the country's labour force. However, $87 \%$ of these small businesses are surviving on a day-to-day basis and they are owned by black people. Women owned $41 \%$ of these. Trends such as these are very significant, as they illustrate both the potential and the challenges for small business growth (Njiro et al. 2010).

SMEs are normally defined by three components i.e. by revenue, assets (excluding fixed property) or the number of employees. Each country has varying cut-off points and these may even vary by industry. South Africa's National Small Business Act (Act No. 102 of 1996) defines SMEs as a 'separate and distinct business entity', and this includes cooperatives and non-governmental organisations (Kennedy, Bounds \& Goldman 2011).

This Act uses the number of employees, the size as well as the annual turnover as measurement criteria. SMEs can be classified as follows:

- Survivalist enterprise: The income that is generated is less than the minimum income standard. Survivalist enterprises include hawkers, vendors and subsistence farmers. Survivalist enterprises are often categorised as part of the micro enterprise sector.

- Micro enterprise: The turnover is less than the stipulated South African value-added tax (VAT) registration limit. These enterprises do not formally register the enterprise and include, for example, spaza shops, minibus taxis and household industries. Micro enterprises employ no more than five people. The word 'spaza' means 'camouflaged' or 'hidden' in township slang and, therefore, 'spaza shop' refers to a camouflaged or hidden shop in a township (Terblanche 1991:37).

TABLE 1: Contribution of South Africa's small and medium enterprises to the economy.

\begin{tabular}{lccc}
\hline Enterprises & Number of firms (\%) & Employment (\%) & GDP (\%) \\
\hline Survivalist & 19.6 & 2.2 & \\
Micro (0) & 31.3 & 3.5 & 5.8 \\
Micro (1-4) & 19.8 & 6.5 & \\
Very small & 20.5 & 13 & 13.9 \\
Small enterprises & 6.8 & 15.7 & 15 \\
Medium enterprises & 1.3 & 13 & 65.2 \\
\hline Large & 0.7 & 46.1 & \\
\hline
\end{tabular}

Source: Falkena, H., n.d., 'SMES' access to finance in South Africa - A supply-side regulatory review', in H. Falkena, (ed.), Financial Services and Regulation, South Africa. GDP, gross domestic product. 
- Very small enterprise: They employ fewer than 10 employees, except for the mining, electricity, manufacturing and construction sectors, in which they employ fewer than 20 employees. These enterprises operate in the formal market and have access to ICT.

- Small enterprise: They employ up to 50 employees. Small enterprises exhibit more complex business practices.

- Medium enterprise: They employee a maximum number of 100 employees, or up to 200 employees for the mining, electricity, manufacturing and construction sectors. These enterprises might have additional management layers (Abor \& Quartey 2010:221).

Another way to classify SMEs is based on the classification methods of the Bolton Committee, which classifies and describes SMEs on the basis of sectors (Abor \& Quartey 2010). In the manufacturing, mining and construction sectors, it includes all companies that have 200 or fewer employees. In the road transport industry, companies are considered to be small when the number of vehicles is five or fewer. Companies operating in retail, wholesale or services are measured on the basis of their annual turnover.

The South African classification of SMEs is substantially different from that of the European definition. SMEs, as per the European definition, imply companies with less than 250 employees (Silvius 2004). The factors that mainly determine if a company is an SME are displayed in Table 2 (European Commission 2012).

An SME in South Africa's SME sector is required to fulfil the following:

[They are] expected to fulfil a number of roles, ranging from poverty alleviation and employment creation to international competitiveness. Not only are these very divergent policy objectives, but the policy instruments introduced to meet these objectives can be equally different, ranging from literacy training to technological advice. (Blueprint Strategy \& Policy (Pty) Ltd 2005:9)

It is now widely accepted that small businesses are the chief contributor to job creation worldwide and this trend is also true of South Africa, as per Table 1.

In South Africa, SMEs contribution is $56 \%$ to the employment in the private sector and $36 \%$ to the gross domestic product (Olawale \& Garwe 2010:729). They also state that small businesses are one of the best ways to address unemployment through the potential of the small business itself to create employment and to promote the development of small businesses.

SMEs also play an important role within townships to uplift the local community and to create jobs. Townships are a

TABLE 2: Factors determining small and medium enterprises status.

\begin{tabular}{lcc}
\hline Company category & Employees & Turnover \\
\hline Medium-sized & $<250$ & $\leq € 50$ million \\
Small & $<50$ & $\leq € 10$ million \\
Micro & $<10$ & $\leq € 2$ million \\
\hline
\end{tabular}

particularly South African phenomena and a deliberate manipulation of former urban planning that designed cities in terms of race. The creation of Soweto, which is a conglomeration of townships, was founded to house mainly black labourers who worked in mines and other industries in the city of Johannesburg. An increasing number of black people were relocated from inner city 'black spots' to Soweto, as the centre of Johannesburg was reserved for white people (Njiro et al. 2010:6). In 1963, after a public four-year competition, the name Soweto was adopted for the South Western Townships (Njiro et al. 2010:6). Apartheid planning did not provide any infrastructure to these settlements and all manner of shelters, including shacks, flourished. Residents had limited access to capital, education and basic social and economic rights. They were also prohibited from owning and running businesses.

\section{According to Njiro et al. (2010):}

Of the 200000 Soweto businesses, about $83 \%$ have turnovers of less than R10 000 a month. The objective is to grow these small businesses into entities with turnovers exceeding R1 million. (p.8)

To achieve this goal of growing MSBs from survivalist and micro enterprises into very small and small enterprises, ICT can be used. ICT is seen as an enabler for business (Mitra 2005). The usage of ICT can reduce the cost of operations and increase profits. This is applicable to any enterprise, irrespective of size. ICT can help MSBs to cut costs through the improvement of internal business processes, improved communication with customers as well as suppliers and an improved supply chain online (Kannabiran \& Dharmalingam 2012:192). ICT can also help MSBs to manage, source, produce, plan and ultimately support decisions in their daily operations.

This is not always the case, however. ICT deployment in many Chinese MSBs resulted in negative performance which is not in parallel with the economic growth that was experienced during the same period. The critical challenges were not caused by the failure of ICT technologies. Rather, inadequate support and business processes were common obstacles in the deployment of ICT (Sidney, Tina \& Choy 2010). Another case in point is Indonesia, where MSBs are one of the economic backbones. In their daily operation some of the MSBs conduct their business using ICT. However, the majority do not use ICT in an optimum way and daily operations are still performed manually (Santosa \& Kusumawardani 2010).

MSBs adopt ICT to achieve efficiency and in response to a variety of environmental and internal pressures (Khalifa \& Davison 2006:275). Moreover, the MSBs most likely to use ICT are very likely to be technically competent already. MSBs do not adopt ICT uniquely as a response to coercive and normative pressures from external and internal sources. They are also strongly motivated by the perceived desirability and feasibility of ICT under consideration.

The literature review indicates that there is a case to be made for the adoption and use of ICT within the day-to-day 
running of an SME. The second part of the literature review focuses on the current models which explain when and why MSBs would adopt and use ICT.

Davis (1989) emphasises that the (1) perceived usefulness and the (2) perceived ease of use determines whether someone will adopt technology or not. This thinking realised the benefits of the technology acceptance model (TAM). This model was further refined by Davis, Bagozzi and Warshaw (1989), who included (1) the attitude towards using and (2) the behavioural intention to use additional aspects of TAM. Figure 1 illustrates TAM.

Various other models have emerged since then, but all of them basically incorporate the original components of TAM (Venkatesh, Morris, Davis \& Davis 2003). To relate this back to MSBs in Soweto, MSBs will only adopt ICT if there is a perception that ICT will assist in the growth and sustainability of the MSB itself and if the perception exists that it is easy to use a specified technology.

Lucchetti and Sterlacchini (2004) classify the adoption of ICT in SMEs into three categories:

1. General-use information and communication technologies (ICTs) include collaboration tools where the rate of adoption is high and do not depend on size (i.e. number of employees) and industry.

2. Production-integrating ICTs include local area network (LAN), electronic data interchange (EDI) and intranet. This type of ICTs is linked to intra and inter-firm production processes; they are more expensive than general-use ICTs and are dependent on relevant technological skills.

3. Market-oriented ICTs are jointly identified by the presence and the content of a firm's web site and are used to improve visibility and provide detailed information of products, with a view to attract potential customers (p. 152).

This is all well and good in the context of a developed nation, but access to ICT in Soweto is not a given. The results from the South African 2012 census highlight the digital divide. The 'proportion of households owning cellphones increased from 31.9\% in 2001 to $88.9 \%$ in 2011' (Statistics South Africa 2012). The proportion of households with computers increased from $8.5 \%$ to $21.1 \%$ between 2001 and 2011, respectively (Statistics South Africa 2012). Figure 2 shows the percentage of South African households that have access to the Internet. A relatively high proportion of these households, $64.8 \%$, have no access to the Internet.

The highest percentage of households reported that cellphones are used to access the Internet (Statistics South Africa 2012). A report on the status of ICT in Africa highlighted the challenges that MSBs face. The main challenges are infrastructure and a growing ICT skills gap (Yonazi et al. 2012).

The review of the literature highlighted two important aspects: (1) MSBs as well as SMEs are important for any country's economy and (2) the adoption of ICT itself can improve the profitability of an MSB.
This leads to the research problem at hand: is ICT, per se, adopted by township MSBs in order to improve the profitability and sustainability of the MSB?

The research is of an exploratory nature and, therefore, the focus is on the actual use of ICT and not necessarily on the causes of technology acceptance. Given the model in Figure 1 , the focus is not on the factors that influence the use of ICT but on the actual adoption of ICT itself. The reason for this is that one first needs to understand a concept before it can be explained.

Given this rationale, the following research questions are posed:

1. What type of ICT is adopted by MSBs in Soweto?

2. Is the adoption of ICT dictated by the type of MSB?

3. Is there a correlation between the type of ICT adopted and the profitability of the MSB?

4. Is ICT applied differently based on the type of MSB?

The following section contains a discussion of the research methodology that was followed to gather the responses.

\section{Research methodology}

Research designs focus on validating the research question through a testing project and can be either quantitative research designs or qualitative research designs (Feilzer 2010; Huizingh 2007). Quantitative research focuses on answering the research question through the collection of numerical data and the statistical analysis of this data (Balnaves \& Caputi 2001; Blaikie 2003).

A structured questionnaire was developed focusing on two aspects: (1) biographical information such as income and type of SME and (2) the type of ICT used, for instance cellphones, as well as the frequency of usage. The types

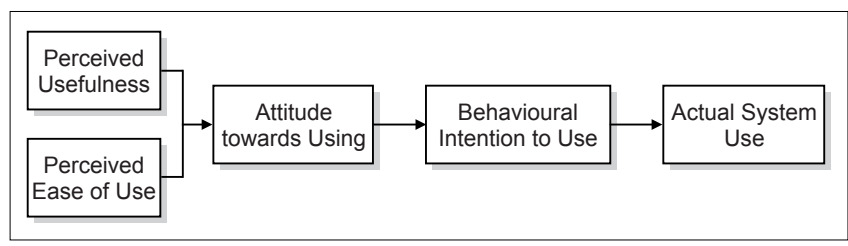

Source: Davis, F.D., Bagozzi, R.P. \& Warshaw, P.R., 1989, 'User acceptance of computer technology: A comparison of two theoretical models', Management Science 35(8), 982-1003. FIGURE 1: Technology acceptance model.

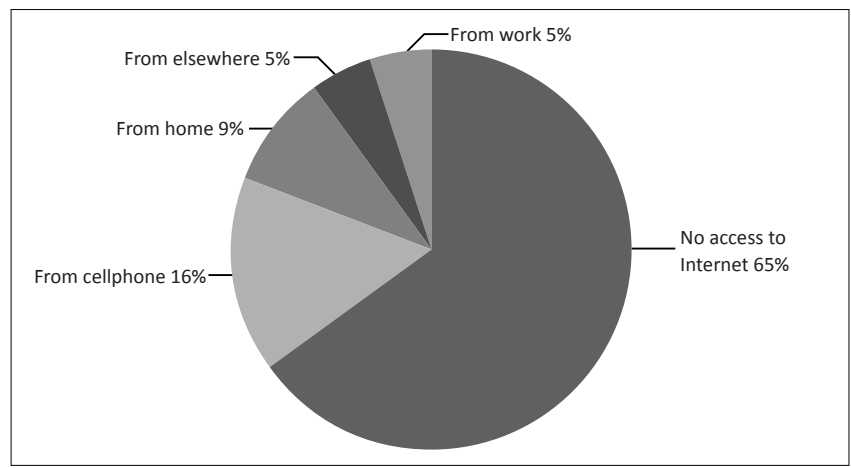

Source: Statistics South Africa, 2012, Census 2011 Statistical Release, Statistics South Africa, Pretoria.

FIGURE 2: Internet access. 
of ICT selected are founded on research, indicating that mobile technology is a main enabling technology (Ngassam, Ntawanga \& Eloff 2013). Building on mobile technology, the next levels of technology are personal computers (PCs), laptops and tablets.

Structured questionnaires make use of closed questions where the results can be analysed quantitatively for patterns and trends. The researcher opted for a structured questionnaire because it ensures that each respondent is presented with exactly the same questions in the same order. This ensures integrity in longitudinal studies as well as comparisons between various subgroups.

TAM, which informs this research, uses 28 questions to measure the perceived usefulness (14 questions) and perceived ease of use (14 questions). The intention is to adopt the TAM questions in a specific environment and for a specific application (Polun et al. 2004). The results can then be used to measure and correlate the perceived usefulness and ease of use. The problem that was faced in Soweto is that there are no data available on the acceptance of ICT and, therefore, the ease of use and usefulness of a specific technology is of no relevance at this point in time. It is important to understand, within the context of Soweto and its ICT adversity, what technologies are currently used as well as the purposes for which they are used. The 28 questions of TAM could, therefore, not be used as they are normally worded, and a shortened structure questionnaire, derived from TAM, was designed. The questions were grouped into two major sections focusing, firstly, on the purpose of the respective technologies and, secondly, on how frequent these technologies are used. The rationale is that the results will then be used to develop in-depth TAM questionnaires for each of the technologies, once there is an understanding of what technologies are used and how frequently.

The questionnaires were administered via a private consulting firm that was familiar with Soweto and the MSBs within the different suburbs. The consulting firm made use of runners to interview the SME owners. The runners were used as a pilot to test the questionnaire to identify potential problems and to make improvements. Using the runners as a pilot scheme, also made them aware of the type of responses that they could expect.

A briefing session was held to explain the questions to the runners, and the types of answers that should be provided by the SME owners. Soweto was divided into its suburbs (33 in total) and 30 SME owners were picked randomly to complete the questionnaire. The owners were chosen on an availability basis as the runners surveyed the suburb. The language of choice used was either English or the native language of the SME owner which consisted, in most cases, of Zulu. The contact details of the SME were also added for follow-up questionnaires and future comparative analysis. A total of 978 completed questionnaires were received. The quality of the responses was of such a nature that all the questionnaires could be used.
The data gathered in this survey were processed and analysed using SPSS, a statistical analysis software package (Argyrous 2011; Huizingh 2007). SPSS is able to perform enhanced data management and has extended reporting capabilities.

Reliability is concerned with how well the survey data can be reproduced, and validity is a measure of how well the survey measures what it is supposed to measure (Kirk \& Miller 1986; Kitchenham \& Pfleeger 2002; Litwin 1995). Some available reliability checks that can be done in a survey are presented by Litwin (1995):

- Test-retest is relevant when a survey is sampled at different points in time (Kitchenham \& Pfleeger 2002). In this research the survey was sampled for the first time; therefore, a test-retest is only possible in future.

- As scales were used in the questionnaire, it was very important to check internal consistency. Internal consistency is a measure when assessing scales are used in the survey (Litwin 1995). Cronbach's alpha is an internal consistency measure and is used to determine whether the scale is reliable or not (Kitchenham \& Pfleeger 2002; Litwin 1995). The Cronbach's alpha coefficient is a reflection of how well the different items complement one another in measuring the same variable (Cronbach 1951; Litwin 1995). The Cronbach's alpha coefficient was calculated for each of the technologies that were used and is presented in Table 3. Internal consistency levels of 0.7 or more are generally accepted as representing good reliability.

The results indicate that there is internal validity apart from the cellphone grouping of questions. The results of this grouping must be interpreted carefully and a retest might highlight some additional inconsistencies.

The purpose of any questionnaire is that it measures what it intended to measure (Cameron \& Price 2009). If a questionnaire does not measure what it is supposed to measure, then the conclusions and statistical analysis might also be invalid. Validity checks are available to verify that the questionnaire is suitable (Kitchenham \& Pfleeger 2002). The types of validity that can be used to assess the survey questionnaire are face, content, criterion and construct validity (Litwin 1995).

The researcher opted for face and content validity. Face validity refers to the 'obviousness' of a test that is the degree to which the purpose of the test is apparent to those taking it.

TABLE 3: Cronbach's alpha reliability tests.

\begin{tabular}{lccc}
\hline ICT adoption & Cronbach's alpha & $\begin{array}{c}\text { Cronbach's alpha } \\
\text { based } \\
\text { on standardised items }\end{array}$ & $N$ of items \\
\hline Cellphone & .570 & .585 & 6 \\
Smartphone & .881 & .876 & 7 \\
PC & .796 & .837 & 6 \\
Laptop & .792 & .845 & 6 \\
Internet & .820 & .836 & 4 \\
\hline
\end{tabular}

$\mathrm{PC}$, personal computer. 
The purpose of this research, as well as the questions, was clear to the respondents and, thus, it can be derived that there is high face validity. Content validity on the other hand focuses on extent to which the items are fairly representative of the entire domain the test seeks to measure. The questionnaire was evaluated by subject matter experts for content validity. The subject matter experts evaluated the questionnaire to ensure that (1) all the relevant technologies are listed, (2) all the relevant applications of the technology are listed and (3) the layout is logical and all relevant questions, required to collect data to answer the research questions, were included. The subject matter experts were information system experts, SME experts in Soweto itself as well as a questionnaire development expert.

Internal validity is the extent to which the questionnaire allows the researchers to draw conclusions about the relationship between variables. Internal validity was tested through various correlations and cross-tabulations. External validity, on the other hand, is the extent to which the sample genuinely represents the population from which it was drawn. In this research the sample was representative as the respondents were all SME owners within Soweto.

The results from this survey can be used with confidence as the reliability and validity of the questionnaire were proven through the reliability and validity tests.

\section{Results and analysis}

The first section of the results focuses on the biographical information of the respondents. It provides an overview of the respondents with regard to their income and type of small business that they own and manage.

The results from Figure 3 indicate that the majority (79.2\%) of the SME owners earned less than R5000 a month.

What is even more astounding is that $43.3 \%$ of the respondents earned less than R2000 a month through their business. These results indicate then that close to $80 \%$ of the MSBs in this survey can be classified as micro enterprises which include survivalist MSBs.

Only $4.4 \%$ of the respondents earned more than R15 000 per month.

The next question on the questionnaire focused on the type of business that the respondents owned. These results are displayed in Figure 4.

Most of the respondents were either spaza shop owners $(24.8 \%)$ or street vendors (23.3\%). A spaza shop normally has a very limited floor area and is operated from a garage, shed or even a bedroom in a township.

Some $30 \%$ of the respondents owned either a tavern or shebeen (places that sell alcohol). Only 3.1\% of the respondents owned a formal franchise. The 'Other' category made up $18.3 \%$ of the remainder of the businesses. MSBs in this grouping include barber shops, hairdressers, daycare, shoe repair and public phone rentals.

Table 4 presents a cross-analysis of the income versus the type of business. It is evident from Table 4 that the more formal the type of MSB or SME, the more income is generated.

Street vendors and spaza shops accounted for $29 \%$ of the income, which was less than R2000 per month.

The results from the biographical data highlight that most of the MSBs can be classified as micro enterprises, where the income was less than R150 000 per year. Only 13.1\% can be classified as small MSBs.

The second part of the analysis focuses on the type of ICT used by the owners of the MSBs, the frequency of the usage as well as the reasons for using the specific technology.

Figure 5 displays the type of ICT used and the frequency of usage. It must be noted that the respondents could select one or more of the listed technologies. The idea was to determine how many technologies were used as well as their frequency of usage.

The results indicate that the 'traditional' technologies were still used most of the time. Normal basic cellphones, without any features, as well as pen and paper were the technologies that were used the most. They were also used on a constant, daily basis. The technology that also featured fairly often ( $82.6 \%$ daily usage) was calculators.

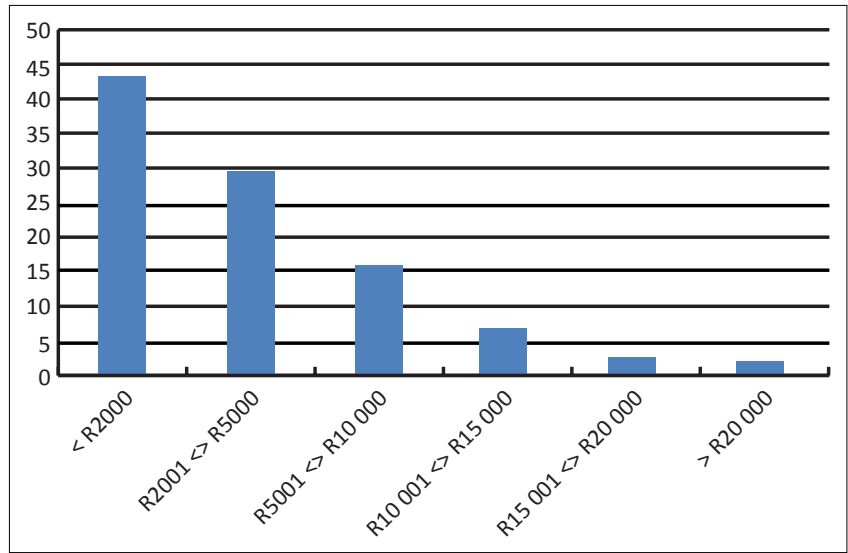

FIGURE 3: Monthly income.

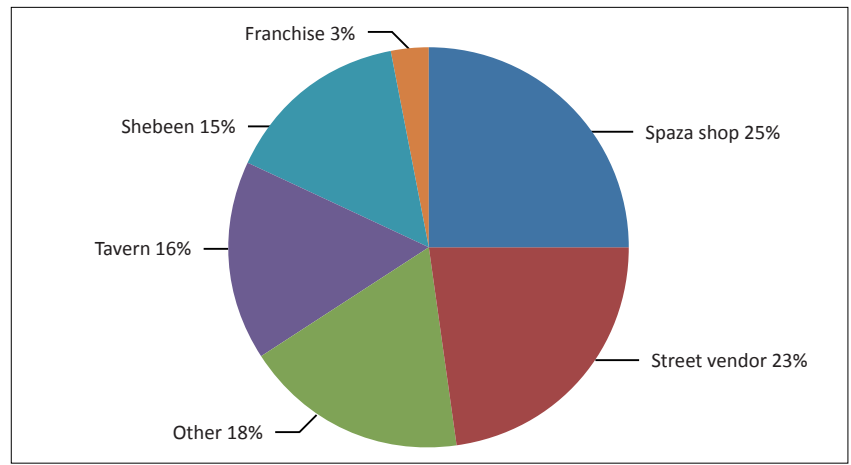

FIGURE 4: Type of business. 
Although statistics indicate that smartphones are infiltrating the cellular market, only $55.3 \%$ of the respondents used them. It is quite peculiar that both cellphones and smartphones were used by the respondents, highlighting the fact that some South Africans have more than one mobile device per person.

On the other side of the scale are the technologies that were not used. These include tablet devices (98.1\% never used), laptops (68.4\% never used) and fax machines (65\% never used). Although these technologies were mostly not used, it must be noted that where they were indeed used, fax machines (19.6\%) and laptops (18\%) were actually used on a daily basis.

The following section provides an analysis of the technologies to determine the purpose for which the specific technology was used.

\section{Type of ICT and usage}

The results indicate that cellphones were used for what they were intended. The respondents used them for normal dayto-day phone calls $(83.2 \%)$ as well as to send SMSs $(61.6 \%)$. The results are depicted in Figure 6.
It is of interest that only a small portion of the respondents used cellphones for business purposes, such as cellphone banking (8\%), email (7.5\%) and Internet banking (2.4\%).

Although the respondents did not use smartphones as much as cellphones, it seems that those who did use them did so more for business-related activities. This indicates a paradigm shift as depicted in Figure 7.

The results must be viewed in relation to the fact that only $55 \%$ of the respondents used a smartphone on a daily basis. The implication is that those respondents who had two phones

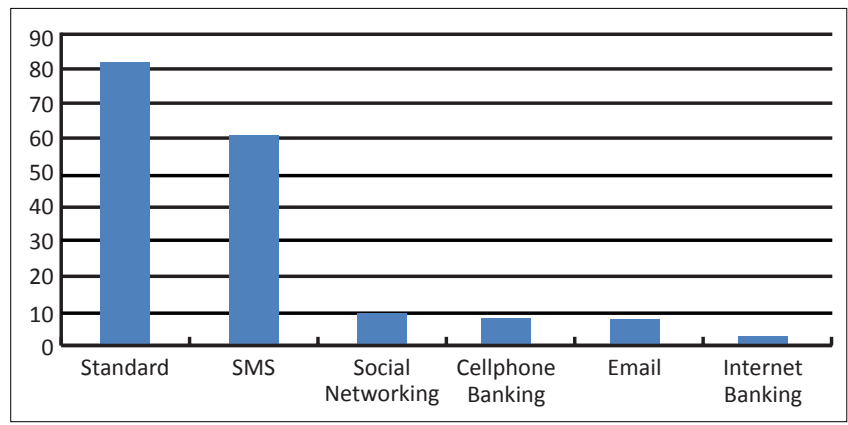

FIGURE 6: Cellphone usage.

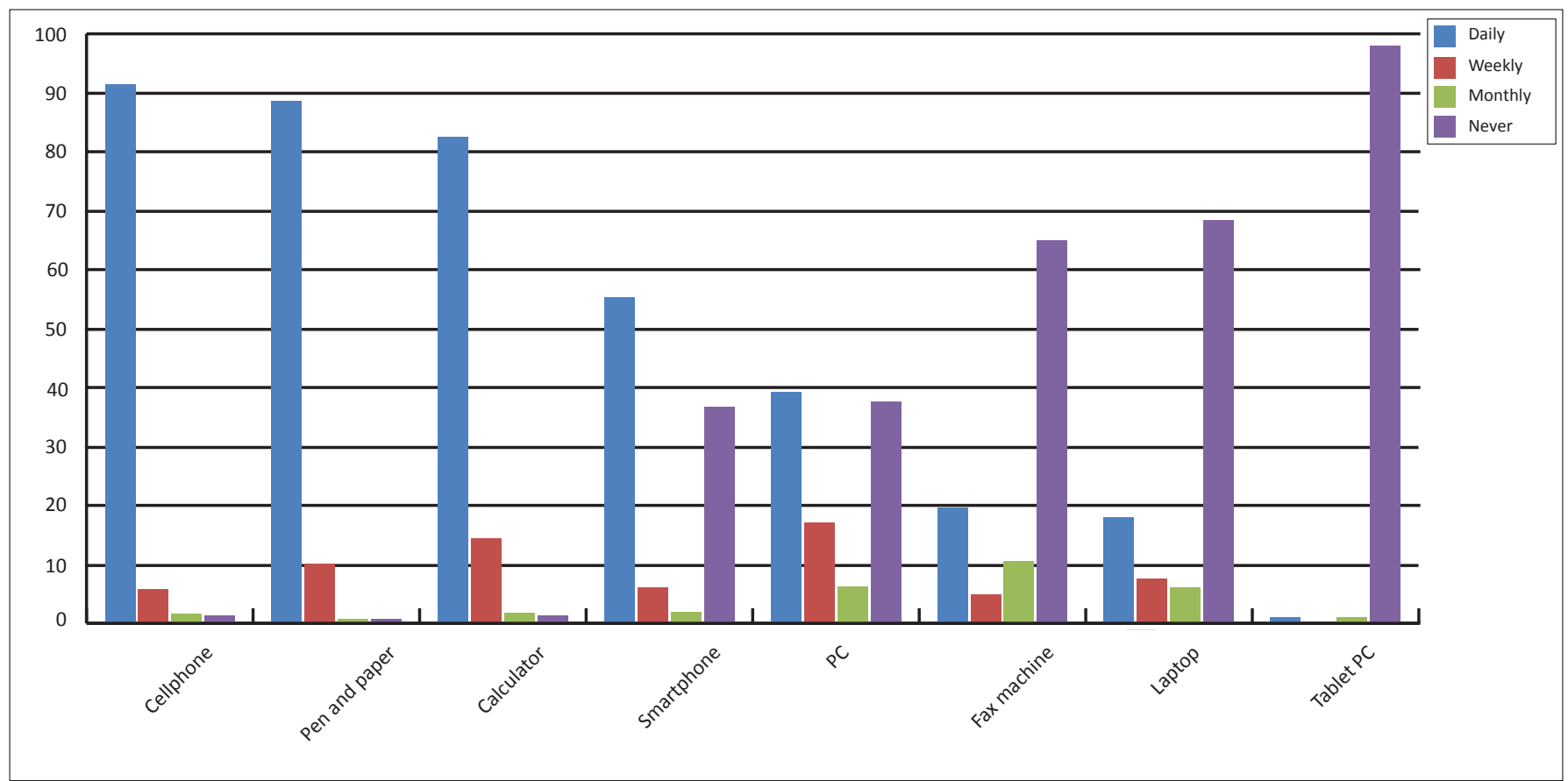

FIGURE 5: Frequency and usage of information and communications technology.

TABLE 4: Cross-analysis of income and type of business.

\begin{tabular}{|c|c|c|c|c|c|c|}
\hline Type of business & $<$ R2000 (\%) & $\begin{array}{l}\text { R2001 } \\
<> \\
\text { R5000 (\%) }\end{array}$ & $\begin{array}{l}\text { R5001 } \\
<> \\
\text { R10 } 000 \text { (\%) }\end{array}$ & $\begin{array}{l}\text { R10 } 001 \\
<> \\
\text { R15 } 000 \text { (\%) }\end{array}$ & $\begin{array}{l}\text { R15 } 001 \\
<> \\
\text { R20 } 000 \text { (\%) }\end{array}$ & > R20 000 (\%) \\
\hline Street vendor & 19.0 & 4.0 & 0.3 & - & 0.1 & - \\
\hline Franchise & 1.0 & 0.4 & 0.2 & 1.0 & 1.0 & 0.3 \\
\hline Shebeen & 4.0 & 7.0 & 3.0 & 1.0 & 0.3 & 0.1 \\
\hline Tavern & 1.0 & 6.0 & 4.0 & 3.0 & 1.0 & 1.0 \\
\hline TOTAL (\%) & 43.00 & 30.40 & 15.50 & 7.00 & 3.50 & 2.60 \\
\hline
\end{tabular}


(a cellphone and smartphone) used the cellphone for normal usage and the smartphone for business-related activities.

When the usage of PCs and laptops are compared, no significant difference in the adoption and usage of the technology can be seen. A chi-squared test was done to test for independence between the usage of PCs and laptops and the results indicated that there is no dependency between the two variables. The $100 \%$ stacked bar in Figure 8 highlights these results.

The results indicate that those respondents who used a PC on a daily basis (39.2\%) did not necessarily use it for businessrelated activities. The usage of laptops paints a similar picture and it is evident that laptops were not significantly used by the respondents. One might speculate that the high crime rate in this area could play a role in this statistic, as it is easy to steal a laptop.

The results, as depicted in Figure 6, clearly indicate that there is no difference between the usage of PCs and laptops. Each of the applications is, per ratio, the same with each technology. Figure 9 also paints an interesting picture. The Internet itself, when it was available, was used for normal browsing (47\%) and social networking (19\%). It was seldom used for Internet banking (10\%) and email (24\%).

This might result from limited Internet access in South Africa, as shown in Figure 2.

The next section investigates the correlations to determine whether or not more formal MSBs are adopting ICT and the purposes of its use.

The technique of multiple responses was used to undertake further analysis. This technique allows the analysis of a number of separate variables at the same time. According to Argyrous (2011:512): 'this is used in situations where the responses of separate variables that have a similar coding scheme all point to the same underlying variable'. In this case, the underlying variables were the four major types of technologies: cellphone, smartphone, PC and laptop. Frequencies and cross-tabulations can be performed with multiple responses.

Figure 10 shows the correlation between the type of ICT usage and the type of SME. The purpose of this correlation was to determine whether or not the more formal MSBs used more high-end technology, such as PCs and laptops.

The results in Figure 10 indicate that the more formal MSBs used more high-end technology than the informal MSBs. Cellphones were used by $47 \%$ of street vendors and spaza shop owners. This is in contrast with MSBs such as taverns (15.1\%), which used cellphones in their day-to-day business operations.

PCs and laptops were, on the other hand, used by more formal MSBs (60.6\% and 59.5\%, respectively). Street vendors and spaza shops used PCs (22.2\%) and laptops $(27.7 \%)$ for business.

Further analysis of the results indicates that the MSBs, which were categorised within the 'Other' group, adopted the usage of PCs and laptops more than the other types of business. It is important to note at this point that $44.1 \%$ of the 'Other' consists of four types of MSBs: hair salons (21.8\%), fast food outlets (10.1\%), barbershops (6.1\%) and Internet cafés (6.1\%). Figure 11 highlights that the other types of MSBs used PCs more for business-related activities than the rest of the MSBs. This might be related to the type of business, for example, fast food outlets might need a PC to transact daily sales.

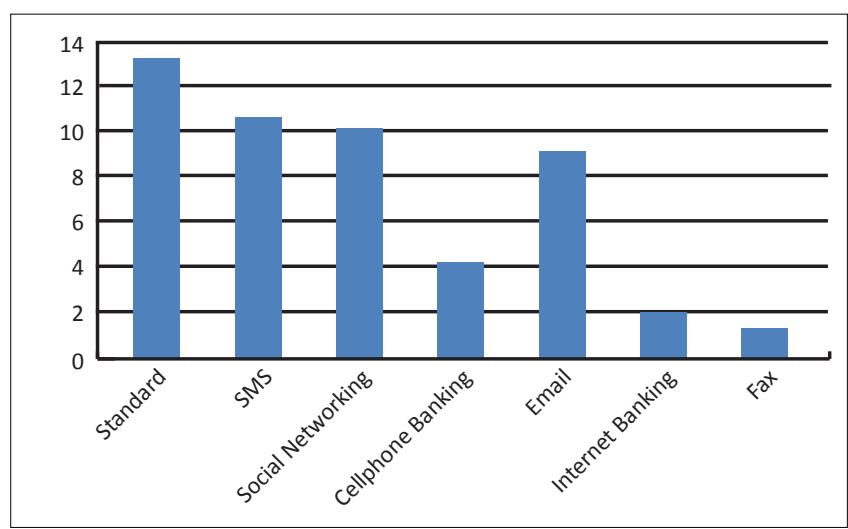

FIGURE 7: Smartphone usage.

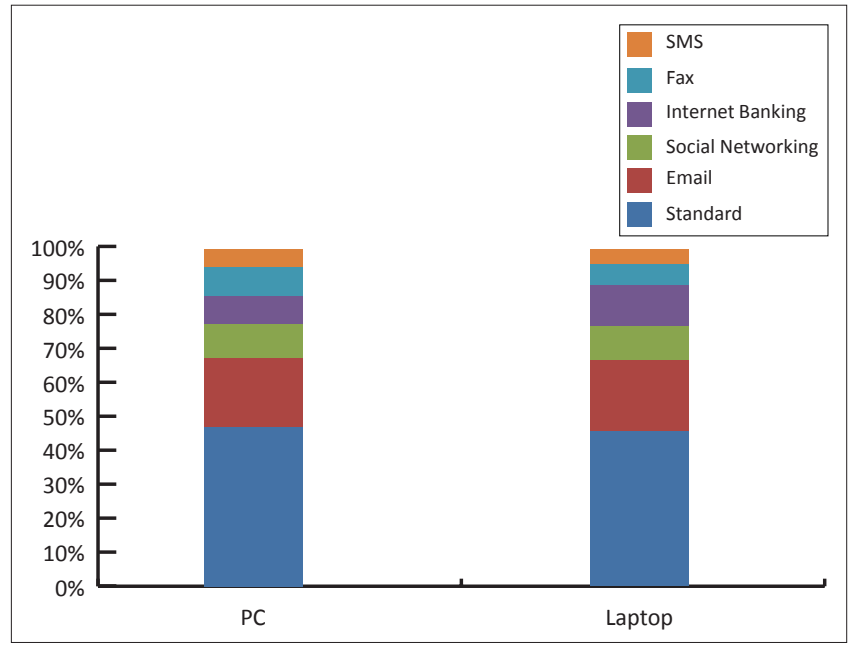

FIGURE 8: Personal computer and laptop usage.

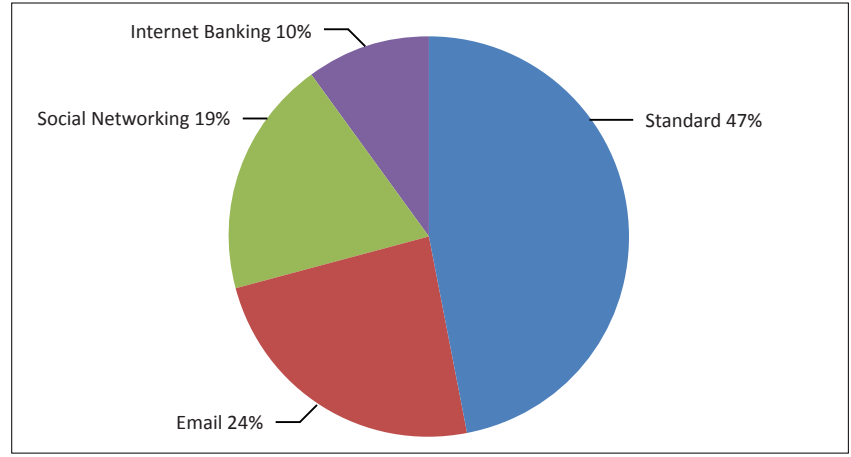

FIGURE 9: Proportional Internet usage. 
Figure 12 tells the same story as with PC usage, where the other types of MSBs used laptops more frequently for business than, for instance, franchises. Table 5 is a comparison between the adoption of cellphones versus smartphones. The comparison is done per type of business.

The results as per Table 5 highlight the two major differences:

1. Cellphones were the preferred technology when the MSB used them for normal usage, such as phoning and sending SMSs. Smartphones, on the other hand, were used when the focus was on business-related transactions, such as Internet banking and emails.

2. The more formal MSBs used smartphones instead of cellphones. Street vendors and spaza shops were more inclined to use cellphones.

The second correlation focuses on the income and the adoption of ICT. As per the literature, the assumption is that the adoption of high-end technology will increase the profits and turnover of the SME. Figure 13 shows the correlation between the monthly income and the type of technology used.

The results clearly highlight this positive correlation between the monthly income and the type of technology adopted by the SME. The monthly income was higher where PCs and laptops were used in the day-to-day running of the SME. This raises an interesting conundrum: must MSBs invest in high-end technology hoping that it will generate money, or is it an evolving concept?

An in-depth analysis of the results indicates that a positive correlation exists between the usage of ICT and the income of the business. ICT is an enabler even in township MSBs.

\section{Discussion}

MSBs play an important role within any economy and even more so within developing economies such as South Africa. The aim of this research was to provide statistical information on the 'raw' rates of ICT adoption amongst MSBs in Soweto. Four research questions were posed and are discussed individually.

The first question focused on the type of ICT adopted by the various MSBs. The results indicate firstly that traditional pen and paper as well as cellphones are the technologies that are mostly used. A calculator is also a technology that is used on a daily basis. The interesting fact is that only a small portion of the MSBs surveyed used PCs and laptops for the daily management and running of their business. Tablet devices were not used at all even when these devices were given to the businesses for free, with the renewal of cellphone contracts. The assumption can be made that the functionality and benefits of tablet devices are not known and realised by the SME owners. This might result from a lack of education. Tablets are also not very useful without a network connection. Tablets with SIM slots are quite expensive and the cheaper versions, with Wi-Fi only, are not useful as there is no Wi-
Fi network available in Soweto. If free $\mathrm{Wi}-\mathrm{Fi}$ is funded by government, private industry or both, there would be an increase in the adoption of these cheaper tablets. The Internet is an essential part in the process of technology adoption.

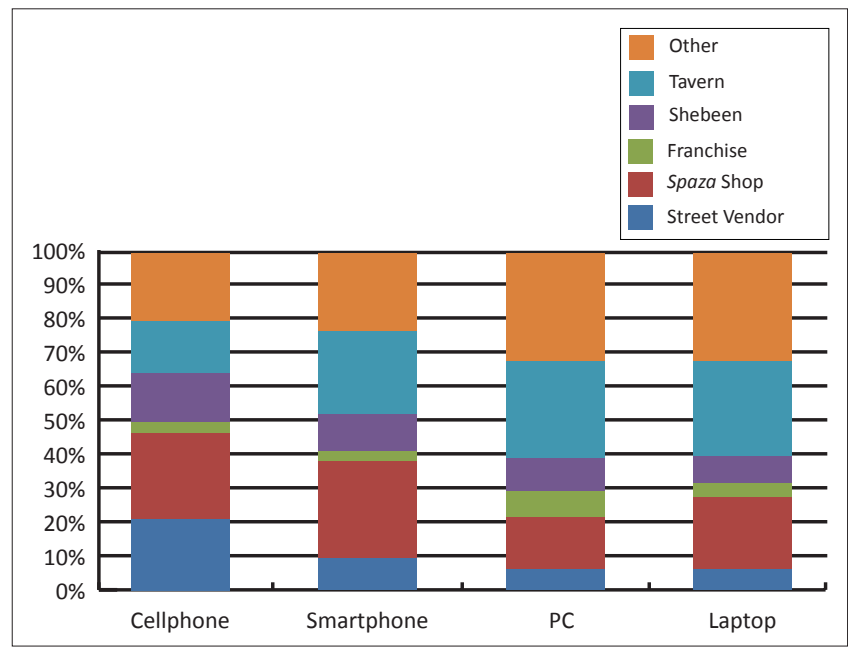

FIGURE 10: Correlation between information and communications technology usage and type of business.

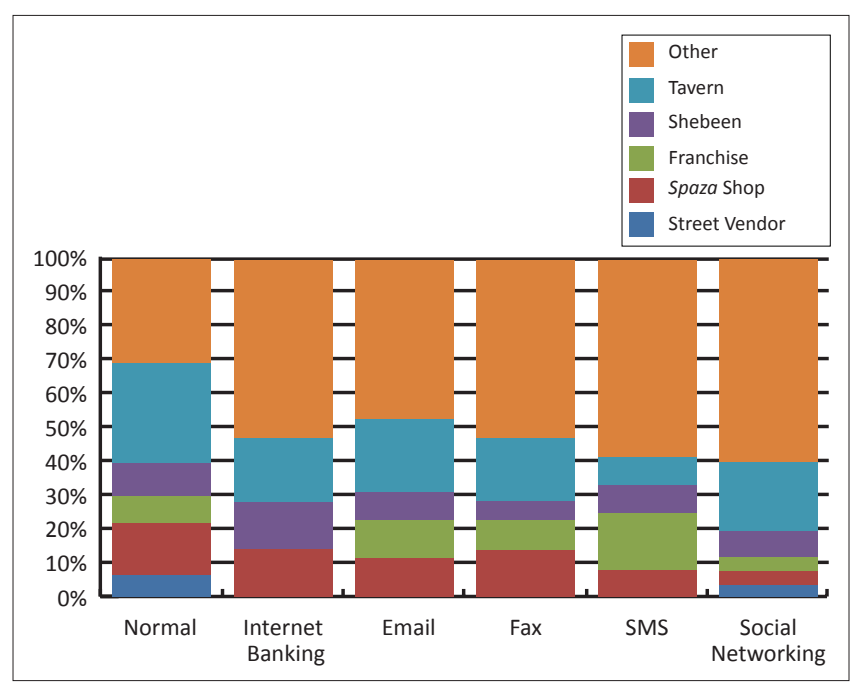

FIGURE 11: Correlation between personal computer usage and type of business.

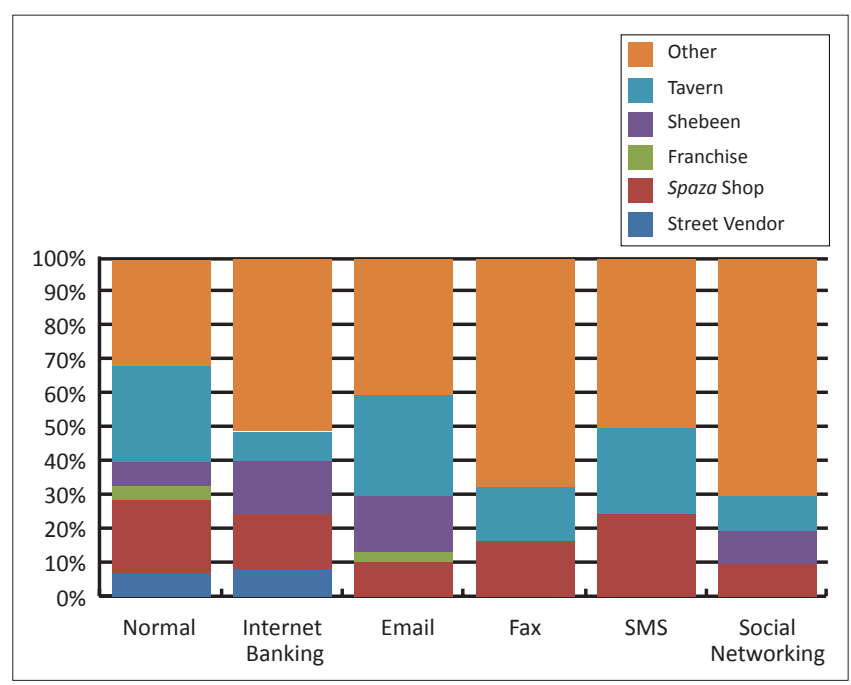

FIGURE 12: Correlation between laptop usage and type of business. 

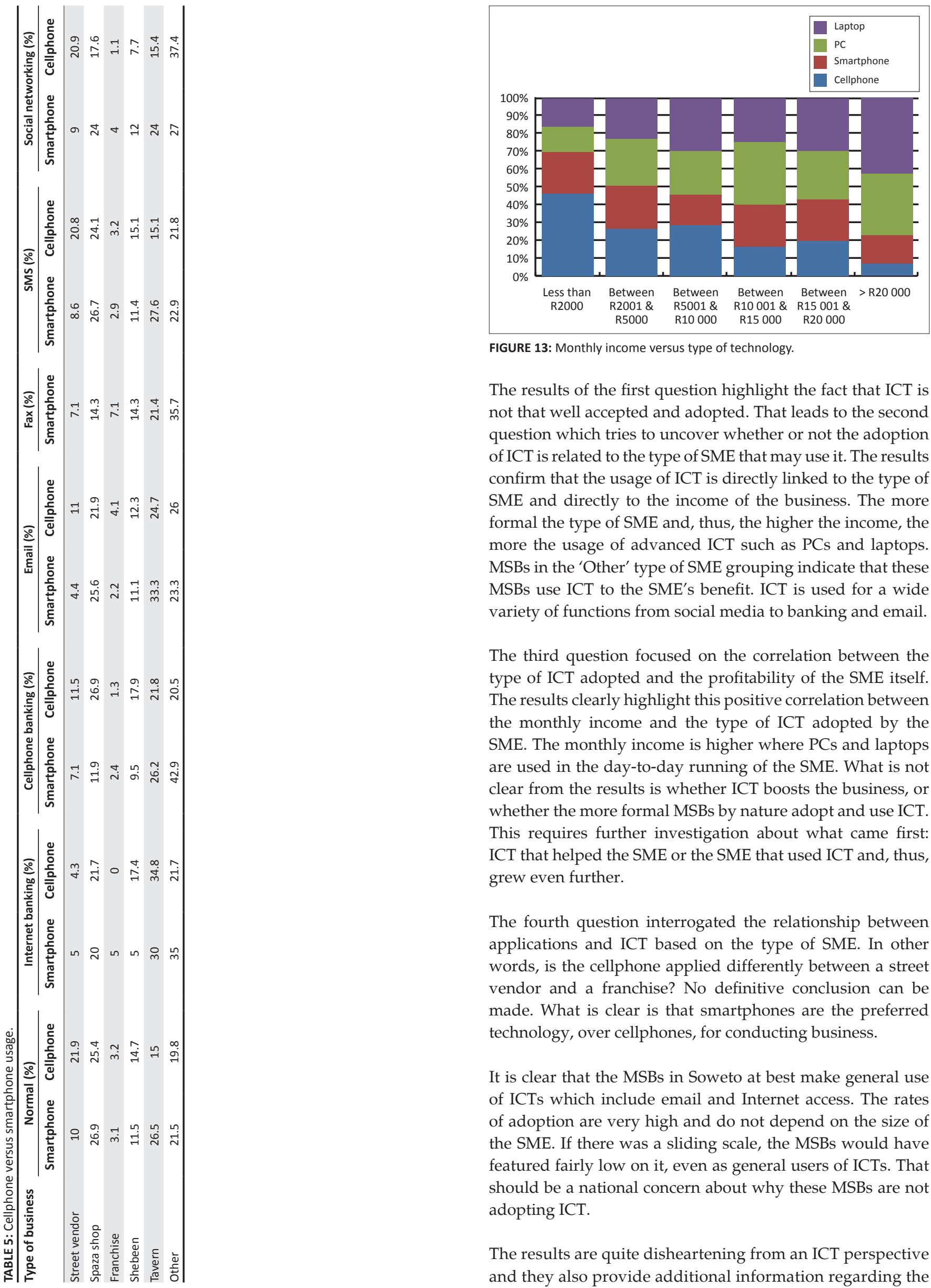

FIGURE 13: Monthly income versus type of technology.

The results of the first question highlight the fact that ICT is not that well accepted and adopted. That leads to the second question which tries to uncover whether or not the adoption of ICT is related to the type of SME that may use it. The results confirm that the usage of ICT is directly linked to the type of SME and directly to the income of the business. The more formal the type of SME and, thus, the higher the income, the more the usage of advanced ICT such as PCs and laptops. MSBs in the 'Other' type of SME grouping indicate that these MSBs use ICT to the SME's benefit. ICT is used for a wide variety of functions from social media to banking and email.

The third question focused on the correlation between the type of ICT adopted and the profitability of the SME itself. The results clearly highlight this positive correlation between the monthly income and the type of ICT adopted by the SME. The monthly income is higher where PCs and laptops are used in the day-to-day running of the SME. What is not clear from the results is whether ICT boosts the business, or whether the more formal MSBs by nature adopt and use ICT. This requires further investigation about what came first: ICT that helped the SME or the SME that used ICT and, thus, grew even further.

The fourth question interrogated the relationship between applications and ICT based on the type of SME. In other words, is the cellphone applied differently between a street vendor and a franchise? No definitive conclusion can be made. What is clear is that smartphones are the preferred technology, over cellphones, for conducting business.

It is clear that the MSBs in Soweto at best make general use of ICTs which include email and Internet access. The rates of adoption are very high and do not depend on the size of the SME. If there was a sliding scale, the MSBs would have featured fairly low on it, even as general users of ICTs. That should be a national concern about why these MSBs are not adopting ICT.

The results are quite disheartening from an ICT perspective and they also provide additional information regarding the 
type and size of the MSBs in Soweto. ICT is particularly easy to use these days and, thus, the adoption of ICT must rely on the perceived usefulness. This can only be overcome through training and education. Sidney et al. (2010) and also Santosa and Kusumawardani (2010) emphasise that there must be an effective implementation strategy that focuses on the deployment of ICT for MSBs. The strategy should serve as a guideline for MSBs to improve they utilise their ICT infrastructure.

The analysis of the results also indicates that although ICT is used by some MSBs, the usage is not necessarily linked to business. ICT is used for its intended purpose, such as word processing, but it is not used or adopted for business requirements such as marketing, Internet banking and financial analysis. It might be a matter of education or ignorance, but this should be researched further.

The results indicate that most MSBs are either survivalists or very small MSBs that barely make a living. It makes logical sense that ICT does not necessarily feature within the framework of such MSBs. However, ICT can, as an enabler, contribute to growing the business and generating more income, and, thus, move the SME to the next level.

\section{Conclusion}

The literature highlights the importance of MSBs within developing economies and their vital role in the growth of the economy. The literature also highlights the importance of ICT as an enabler for business and the argument is, thus, that ICT can or should enable MSBs to grow themselves and, thus, stimulate the economy of a country such as South Africa.

The findings indicate that the adoption and use of ICT are directly linked to the income of the respective MSBs. The more formal MSBs use more advanced technologies such as PCs and laptops, whereas the smaller MSBs revert back to pen and paper, calculators and cellphones. Another aspect that was highlighted is the fact that ICT, when it is utilised, is not fully utilised. An example is cellphones which are used mostly for normal, non-business purposes. The SME owners have not yet made the transition from traditional usage of cellphones and the intent, to applying these for business usage and growing the business. A startling aspect is that most of the MSBs are survivalist MSBs, focusing as such more on surviving and not necessarily on growing the business.

It can be concluded that work remains to be completed concerning training on and insight into the usage of ICT. The results highlight the fact that SME owners do not necessarily know what they can do with ICT and how it can grow their business. A possible solution is to liaise with the local business chambers within Soweto and provide the necessary training and awareness as a continued effort and not just a once-off scenario.

It is the first time that such research has been performed within a South African township and the results are significant for future research. The results from this research open an entirely new world of research possibilities. Various areas of research never addressed before have also been highlighted.

Future research should include a more in-depth analysis of why ICT is not used for business, and what those various barriers are to entering the world of ICT. This was not covered by this research, as the aim was to establish a common understanding of the problem at hand. The technology adoption model (TAM) is a causal model and can, thus, be used to test certain hypotheses. Future research can also be expanded to other South African townships to determine the differences between the various populations.

For township MSBs to embrace ICT and use it to the fullest, the full potential of ICT must be advocated and the benefits must be worthwhile. If this is not achieved with a concerted effort, then the digital divide will not be crossed by MSBs and they will not benefit from the potential growth and market share. ICT might help most of the MSBs to move from survivalist to micro enterprises where they can start employing other township people and, thus, reduce the unemployment statistics of South Africa.

\section{References}

Abor, J. \& Quartey, P., 2010, 'Issues in SME Development in Ghana and South Africa', International Research Journal of Finance \& Economics 39, 218-228.

Arendt, L., 2008, 'Barriers to ICT adoption in SMEs: How to bridge the digital divide?', Journal of Systems and Information Technology 10, 93-108. http://dx.doi. org/10.1108/13287260810897738

Argyrous, G., 2011, Statistics for research with a guide to SPSS, Sage Publications, London.

Balnaves, M. \& Caputi, P., 2001, Introduction to quantitative research methods - An investigative approach, Sage Publications, London.

Beck, T., Demirguc-Kunt, A. \& Levine, R., 2005, 'SMEs, growth, and poverty: Crosscountry evidence', Journal of Economic Growth 10(3), 199-229. http://dx.doi. org/10.1007/s10887-005-3533-5

Blaikie, N., 2003, Analyzing Quantitative Data - From Description to Explanation, Sage Publications, London.

Blueprint Strategy \& Policy (Pty) Ltd., 2005, Promotion of small and medium enterprises in the South African chemicals sector, Blueprint Strategy \& Policy (Pty) Ltd., South Africa.

Cameron, S. \& Price, D., 2009, Business research methods - A practical approach, Chartered Institute of Personnel and Development, London.

Cravo, T., Gourlay, A. \& Becker, B., 2012, 'SMEs and regional economic growth in Brazil', Small Business Economics 38(2), 217-230. http://dx.doi.org/10.1007/ s11187-010-9261-z

Cronbach, L., 1951, 'Coefficient alpha and the internal structure of tests', Psychometrika 16(3), 297-334. http://dx.doi.org/10.1007/BF02310555

Davis, F.D., 1989, 'Perceived Usefulness, Perceived Ease of Use, and User Acceptance of Information Technology', MIS Quarterly 13(3), 319-340. http://dx.doi. org/10.2307/249008

Davis, F.D., Bagozzi, R.P. \& Warshaw, P.R., 1989, 'User acceptance of computer technology: A comparison of two theoretical models', Management Science 35(8), 982-1003. http://dx.doi.org/10.1287/mnsc.35.8.982

European Commission, 2012, 'Small and medium-sized enterprises (SMEs): What is an SME?', European Commission, viewed 04 June 2012, from http://ec.europa. eu/enterprise/policies/sme/facts-figures-analysis/sme-definition/index en.htm

Falkena, H., n.d., 'SMES' access to finance in South Africa - A supply-side regulatory review', in H. Falkena, (ed.), Financial Services and Regulation, South Africa.

Feilzer, Y.M., 2010, 'Doing mixed methods research pragmatically: Implications for the rediscovery of pragmatism as a research paradigm', Journal of Mixed Methods Research 4(1), 6-16. http://dx.doi.org/10.1177/1558689809349691

Hotho, S. \& Champion, K., 2011, 'Small businesses in the new creative industries: Innovation as a people management challenge', Management Decision 49(1), 29-54. http://dx.doi.org/10.1108/00251741111094428

Hu, Q. \& Plant, R., 2001, 'An empirical study of the casual relationship between IT investment and firm performance', Information Resources Management Journal 14(3), 15-26. http://dx.doi.org/10.4018/irmj.2001070102 
Huizingh, E., 2007, Applied statistics with SPSS, Sage Publications, London.

Kannabiran, G. \& Dharmalingam, P., 2012, 'Enablers and inhibitors of advanced information technologies adoption by SMEs: An empirical study of auto ancillaries in India', Journal of Enterprise Information Management 25(2), 186-209. http:// dx.doi.org/10.1108/17410391211204419

Kennedy, C., Bounds, M. \& Goldman, G., 2011, 'Strategic planning in SMEs: conscious effor or afterthought?', in G. Goldman \& G. Heyns (eds.), The 4th International UJ Faculty of Management Conference, 29-31 May 2012, Faculty of Management, University of Johannesburg, Amanzingwe Lodge, Broederstroom, Gauteng, South Africa.

Khalifa, M. \& Davison, M., 2006, 'SME adoption of IT: the case of electronic tradin systems', IEEE Transactions on Engineering Management 53(2), 275-284. http:// dx.doi.org/10.1109/TEM.2006.872251

Kirk, J. \& Miller, M.L., 1986, Reliability and validity in qualitative research, Sage Publications, Beverly Hills.

Kitchenham, B. \& Pfleeger, S.L., 2002, 'Principles of survey research part 4 Questionnaire evaluation', SIGSOFT Softw. Eng. Notes 27(3), 20-23. http://dx.doi. org/10.1145/511152.511155

Litwin, M.S., 1995, How to measure survey reliability and validity, Sage Publications, London.

Lucchetti, R. \& Sterlacchini, A., 2004, 'The adoption of ICT among SMEs: Evidence from an Italian survey', Small Business Economics 23(2), 151-168. http://dx.doi. org/10.1023/B:SBEJ.0000027667.55821.53

Mahembe, E., 2011, Literature review on small and medium enterprises' access to credit and support in South Africa, National Credit Regulator, South Africa.

Mbonyane, B.L., 2006, An exploration of factors that lead to failure of small businesses in the Kagiso, M.Tech Business Administration, UNISA, Pretoria.

Mitra, S., 2005, 'Information Technology as an Enabler of Growth in Firms: An Empirical Assessment', Journal of Management Information Systems 22(2), 279-300.

Ngassam, E.K., Ntawanga, F. \& Eloff, J.H.P., 2013, 'A roadmap for rural area ICT solution deployment: A Case of Kgautswane community in South Africa', The African Journal of Information Systems 5(2), 9-64.

Njiro, E., Mazwai, T. \& Urban, B., 2010, 'A situational analysis of small businesses and enterprises in the townships of the Gauteng province of South Africa,' in 2010 Soweto International Conference on Entrepreneurship \& Development, Soweto, Johannesburg.

Olawale, F. \& Garwe, D., 2010, 'Obstacles to the growth of new SMEs in South Africa: A principal component analysis approach', African Journal of Business Management $4(5), 729-738$
Polun, C., Yueh-Shuang, H., Yuann-Meei, T., Yiing-Yiing, S., Hou, I.C. \& Wei-Fong, K., 2004, 'The development of intelligent, triage-based, mass-gathering emergency medical service PDA support systems', Journal of Nursing Research

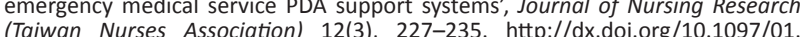
Taiwan Nurses Association

Premkumar, G. \& Roberts, M., 1999, 'Adoption of new information technologies in rural small businesses', Omega 27(4), 467-484. http://dx.doi.org/10.1016/S03050483(98)00071-1

Santosa, P.I. \& Kusumawardani, S.S., 2010, 'Improving SME ICT utilization through industrial attachment program: Indonesia case', in Frontiers in Education Conference (FIE), 2010 IEEE, 27-30 Oct. 2010, S1J-1-S1J-5.

SBP., 2013, SME growth index 2012 headline report. easier/harder for small business in South Africa? SBP, Johannesburg.

Sidney, K.T.T., Tina, A.B. \& Choy, K.L., 2010, 'Efficacy of IT/IS deployment in small- and medium enterprise in China', in 2010 8th International Conference on Supply Chain Management and Information Systems (SCMIS), 6-9 October, 2010, Lisbon, Portugal, pp. 1-7.

Silvius, G., 2004, 'IT and small business: An unhappy marriage?', in M. KhosrowPour (ed.), Innovations through information technology, Idea Group Publishing, Hershey.

Statistics South Africa, 2012, Census 2011 statistical release, Statistics South Africa, Pretoria.

Terblanche, N.S., 1991, 'The spaza shop: South Africa's first own black retailing institution', International Journal of Retail \& Distribution Management 19(5), 37-43. http://dx.doi.org/10.1108/EUM0000000002949

The World Bank, 2006, Information and Communications for Development - Globa Trends and Policies, The World Bank, Washington D.C.

Thong, J.Y.L. \& Yap, C.S., 1995, 'CEO characteristics, organizational characteristics and information technology adoption in small businesses', Omega 23(4), 429-442. http://dx.doi.org/10.1016/0305-0483(95)00017-I

Thurik, R. \& Wennekers, S., 2004, 'Entrepreneurship, small business and economic growth', Journal of Small Business and Enterprise Development 11(1), 140-149. http://dx.doi.org/10.1108/14626000410519173

Venkatesh, V., Morris, M.G., Davis, G.B. \& Davis, F.D., 2003, 'User acceptance of information technology: Toward a unified view', MIS Quarterly 27(3), 425-478.

Yonazi, E., Kelly, T., Halewood, N. \& Blackman, C., 2012, The transformational use of information and communication technologies in Africa, eTransfrom Africa. 